\title{
Tres áreas en la evolución de la regulación del impacto ambiental
}

\author{
Three topics to the evolution of the environmetal impact \\ assessment
}

VITO VERNA CORONADO*

Resumen: El artículo identifica tres áreas para evaluar mejoras a la regulación del Sistema Nacional de Evaluación de Impacto Ambiental, con miras a favorecer la aparición de confianza ciudadana respecto de la certificación ambiental. La primera tiene que ver con transitar gradualmente del paradigma preventivo al integrativo como finalidad de los instrumentos que componen el sistema; la segunda, con enriquecer la evaluación del estudio de impacto ambiental (EIA) incorporándole una etapa de scoping a cargo del Estado; y la tercera, con adoptar medidas adicionales que refuercen la independencia de los equipos de elaboración y evaluación del EIA.

Palabras clave: estudio de impacto ambiental - evaluación de impacto ambiental - certificación ambiental - sistema nacional de evaluación de impacto ambiental

Summary: The paper identifies three topics in order to evaluate the improvements in the regulation of the National System of Environmental Impact Assessment, looking to benefit the people's trust in the environmental certification. The first one consists in the gradual transition from the prevention paradigm to the integration one, as the purpose of the different instruments that compose the system; the second involves the enrichment in the evaluation of the Environmental Impact Study (EIS), by incorporating the scoping phase; and the third involves adopting additional measures that reinforce the independence of the teams in charge of the elaboration and evaluation of the EIS.

Keywords: environmental impact study - environmental impact assessment environmental certification - national system of environmental impact assessment

* Abogado, magíster en Economía y Management Ambiental; responsable del Área Ambiental del Estudio Grau Abogados, profesor del Departamento de Derecho de la Pontificia Universidad Católica del Perú y de la Universidad Peruana de Ciencias Aplicadas (UPC). Con mucha alegría, deseo agradecer y reconocer la ayuda recibida por parte de Mauricio Black, Johanna Romero, Carlos Torres y Víctor La Madrid, jóvenes integrantes del Área Ambiental del Estudio Grau Abogados, por su valioso y sacrificado aporte a este humilde trabajo. Correo electrónico: vverna@ estudiograu.com 
Y LA PERCEPCIÓN SOCIAL.- II.4. LA EVALUACIÓN DE IMPACTO AMBIENTAL.II.4.1. SCOPING Y TÉRMINOS DE REFERENCIA.- III. RECOMENDACIONES REGULATORIAS PARA EL SISTEMA NACIONAL DE EVALUACIÓN DE IMPACTO AMBIENTAL.- III.1. FINALIDAD DEL SISTEMA NACIONAL DE EVALUACIÓN DE IMPACTO AMBIENTAL Y LA EVALUACIÓN AMBIENTAL ESTRATÉGICA.III.2. EL SCOPING Y LOS TÉRMINOS DE REFERENCIA.- III.3. INDEPENDENCIA DE LOS EQUIPOS DE ELABORACIÓN Y EVALUACIÓN DEL ESTUDIO DE IMPACTO AMBIENTAL.

\section{INTRODUCCIÓN}

El presente artículo es el resultado del intento por construir recomendaciones para la mejora del marco regulatorio del Sistema Nacional de Evaluación de Impacto Ambiental (SEIA). Estas recomendaciones serán derivadas de los rasgos esenciales de los derechos ambientales, las políticas públicas ambientales, el estudio de impacto ambiental y la evaluación de impacto ambiental; ello con la finalidad de contribuir a la generación de confianza ciudadana a partir de la expedición de la certificación ambiental.

La inquietud que motiva la presente reflexión nace de los problemas de confiabilidad que actualmente despierta la certificación ambiental, acto administrativo destinado a declarar la viabilidad ambiental y social de los proyectos, tanto públicos como privados, en el marco del SEIA.

Cabe precisar que el autor es consciente de que la confianza en la certificación ambiental del Estado depende de una serie de variables y de que estas no necesariamente tienen que ver con aspectos involucrados en el EIA, el SEIA o la regulación. Sin embargo, considera que fijar la confianza como objetivo último de la certificación ambiental coadyuva a alinear su regulación a uno de los logros máximos de las instituciones públicas: alcanzar y mantener la confianza de la población en su trabajo.

\section{MARCO DEL ANÁLISIS}

\section{II.1. Los derechos ambientales}

El reconocimiento del derecho a un medio ambiente adecuado proviene de la comprensión de la vinculación vital que existe entre los seres humanos y su medio ambiente. Todos nosotros somos, al igual que los demás seres vivos, componentes del sistema ambiental e interactuamos permanentemente con él. En esta medida, nuestra calidad de vida, salud, bienestar y hasta la funcionalidad de nuestros sistemas sociales, culturales y económicos dependen del equilibrio ecosistémico. Cada vez más, y con mayor frecuencia, somos testigos de las consecuencias que puede producir una sequía o abundancia de lluvias en los precios de los alimentos, o 
de la forma en que el cambio climático alterará nuestras vidas, hábitos cotidianos e ingresos económicos en el mediano y largo plazo.

Esta constatación, evidentemente, se refleja en el Derecho, en razón de ello, el disfrute del derecho a la paz, a la integridad personal, a la salud, a la vida, a la propiedad, al trabajo, entre muchos otros, depende también del equilibrio de los ecosistemas.

Pero no solo ello, tal como lo expone el numeral 2 del artículo 6 de la Declaración del Derecho al Desarrollo, adoptada por la Asamblea General de las Naciones Unidas en 1986, «todos los derechos humanos y libertades fundamentales son indivisibles e interdependientes ${ }^{1}$. Del mismo modo, el principio 25 de la Declaración de Río de Janeiro proclama que «la paz, el desarrollo y la protección del medio ambiente son interdependientes e inseparables» ${ }^{2}$.

Los ecosistemas, además de su relación más o menos evidente con la salud y la vida, prestan fundamentales servicios a la actividad económica, los cuales hacen posible su expansión y crecimiento. En efecto, la provisión de materia prima a los sistemas productivos, así como la capacidad de asimilación, degradación y dispersión de los desechos de la producción y el consumo son solo algunos ejemplos de lo que el ambiente hace por la economía mundial y a la vez, la prueba concreta de la dependencia que tiene esta respecto de la funcionalidad equilibrada del ambiente.

Sobrepasar la capacidad ambiental de «procesar» naturalmente los desechos y proveernos materia o energía tendrá inevitablemente consecuencias. Estas se traducirán jurídicamente en vulneraciones a nuestros derechos y económicamente en externalidades ambientales negativas ${ }^{3}$.

Eduardo García Villegas, en su artículo «Anotaciones sobre derechos humanos ambientales», afirma que «en un sentido amplio, los derechos humanos ambientales son casi todos, pues los impactos ambientales no se pueden desvincular prácticamente de ninguna de las actividades humanas reguladas por el derecho» ${ }^{4}$. Asimismo, los derechos ambientales se encuentran entrelazados entre sí y con el medio ambiente, en razón de ello, su goce efectivo se encuentra condicionado a la funcionalidad armónica de los ecosistemas. Esta realidad subraya la importancia del

1 ORganización de LAS NAcIONES UnIDAS. Declaración del Derecho al Desarrollo, (http://www2.ohchr. org/spanish/law/desarrollo.htm), 1986.

2 ORGANIZACIÓN DE LAS NACIONES UNIDAS. Declaración de Río de Janeiro, (http://siga.jalisco.gob.mx/ assets/documentos/TratadosInt/DeclaraRio_92.htm), 1992.

3 «Formalmente se dice que existen externalidades cuando las funciones de producción y/o de utilidades de los agentes económicos dependen de las decisiones tomadas por otros agentes sin que medie contraprestación económica» (LABANDEIRA, Xavier \& otros. Economía ambiental. Madrid: Pearson Educación, 2007, p. 70).

4 García VILlegas, Eduardo. «Anotaciones sobre derechos humanos ambientales». En AUtORES VARIOS. Lecturas sobre Derecho del Medio Ambiente. Tomo 3. Bogotá: Universidad Externado de Colombia, 2003, p. 285. 
enfoque sistémico en la compresión de la realidad jurídica, económica y científica actual.

Desde la perspectiva sistémica, los derechos ambientales se encuentran vinculados entre sí y su disfrute depende de las condiciones ambientales imperantes, las cuales pueden ser conocidas a través de las ciencias y sus métodos para producir conocimiento. En este orden de ideas, evaluar la vigencia de los derechos ambientales de la población implica, muchas veces, recurrir al establecimiento de parámetros estandarizados de medición, los cuales deben ser confrontados con monitoreos expresados en valores comparables. Ello da cuenta de la complementariedad, cada vez más necesaria, entre las ciencias jurídicas y las demás ciencias, complementaridad cuya finalidad es producir nuevos saberes sobre el goce efectivo por parte de la comunidad de los derechos ambientales.

\section{II.2. Políticas ambientales}

El 23 de mayo de 2009 se aprobó la Política Nacional del Ambiente, la cual expresa en su estructura y materia involucrada la enorme complejidad de los desafíos ambientales trazados. Gestionar racional e integralmente los recursos naturales, preservar o recomponer la calidad ambiental, o promover las potencialidades que nos ofrece el ambiente para mejorar la competitividad de nuestra economía son objetivos cuya realización implica una aproximación transectorial, sistémica y compleja; todos ellos rasgos esenciales y característicos de la gestión ambiental.

Encontramos, entre otras muchas tareas que supone la gestión ambiental, las siguientes: generar condiciones de acceso y participación equitativa en los beneficios del aprovechamiento de los recursos genéticos, alcanzar una gestión integral y sostenible de los recursos hídricos, alcanzar el uso seguro de la biotecnología, caracterizar la aptitud del territorio a través de la zonificación ecológica económica, sensibilizar a la población frente a la necesidad de adaptarse al cambio climático, desarrollar instrumentos y metodologías para la valoración de los servicios ambientales, lograr el aprovechamiento sostenible de los recursos naturales renovables y no renovables, remediar o recuperar zonas ambientalmente degradadas, prepararnos para afrontar los riesgos naturales o ambientales, promover una producción limpia y la ecoeficiencia, e incorporar el enfoque intercultural en la gestión ambiental. Realizar dichas tareas implica la acción de una serie de competencias, disciplinas y ciencias.

Gran parte de las disciplinas del saber humano se dan cita y colaboran en la realización del objetivo o la política ambiental. No solo las ciencias naturales contribuyen con sus hallazgos a la conservación de un entorno adecuado, la ingeniería, la economía, el derecho, la medicina, la sociología, la antropología, la educación, la administración y la 
psicología, todas mantienen y ensanchan cada vez más su lugar en la consecución de un planeta cada vez más funcional, capaz de albergar a una población todavía creciente en número y necesidades. Población que tiene el reto de construir nuevos hábitos de vida y consumo compatibles con su entorno. La realización de los objetivos de la política ambiental congrega la acción integrada y coordinada de las ciencias naturales y sociales, exactas o no, no solo en la búsqueda de nuevas tecnologías, innovaciones técnicas y tecnológicas o novedosas pruebas, sino también en la necesidad de producir nuevos paradigmas, nuevos principios, nuevos valores y consecuentemente nuevas reglas que nos permitan seguir manteniendo el equilibrio ambiental global y local o, dicho en otras palabras, la vigencia efectiva del derecho fundamental al medio ambiente adecuado.

Los objetivos ambientales, al igual que los derechos ambientales, se juegan tanto en las grandes decisiones sobre mega proyectos, como en las pequeñas decisiones cotidianas de consumo y disposición de desechos de siete mil millones de personas. La política ambiental constituye la integración de varias políticas y múltiples instrumentos de gestión en diferentes campos del actuar humano, organizados de tal forma que recreen la relación entre sistemas sociales, económicos y ambientales altamente complejos. En consecuencia, lo ambiental exige síntesis y no especialidad, enfoque sistémico para comprender y no división para analizar. Lo ambiental resulta ser la conjunción de pensamientos, saberes, disciplinas, políticas, instrumentos, intenciones y un largo etcétera, dispuestos a mantener el equilibrio y funcionalidad de los ecosistemas, los cuales mantienen nuestra economía en expansión, nuestra vida en desarrollo y la vida de los demás seres en permanente evolución.

Por otro lado, las políticas ambientales han experimentado una interesante evolución. Al respecto, resulta interesante citar el caso europeo, continente que se inició en la elaboración de políticas ambientales en 1972. Gómez Orea considera que:

Los dos primeros [programas de acción] se centraron en medidas orientadas a la reparación de daños ambientales, el tercero (19821986) adoptó el principio de prevención, el cuarto (1986-1992) perseguía la integración sistemática de la política ambiental en el resto de las políticas comunitarias y la elaboración de nuevas normas ambientales, el quinto plan entiende que el medio ambiente y el desarrollo son indisolubles, adoptándose la expresión desarrollo sostenible ${ }^{5}$.

5 Gómez OrEA, Domingo. Evaluación de impacto ambiental. Un instrumento preventivo para la gestión ambiental. Segunda edición. Madrid: Ediciones Mundi-Prensa, 2002, p. 69. 
Finalmente, el citado autor opina que el sexto plan (2001-2010) «adopta un enfoque estratégico orientado a influir en la toma de decisiones de empresas, consumidores, políticos y ciudadanos ${ }^{6}$.

Siguiendo a este autor, la evolución de las políticas ambientales nos indica un cambio en los paradigmas - sin que ello suponga el abandono de los anteriores - desde uno primero, que podríamos calificar como reactivo, dirigido a reparar lo dañado, a otro anticipativo y preventivo, que inspiró el tercer programa de acción europeo. El cuarto programa le otorga énfasis al principio de integración, por el cual lo ambiental se reconcilia con su esencia sistémica y transversal, mientras que el quinto programa busca la fusión del desarrollo con el ambiente, en la lógica planteada en el Informe Brundtland?. Para el sexto programa, el paradigma del desarrollo sostenible se mantiene y se dirigen esfuerzos para influenciar, desde etapas cada vez más tempranas, la toma de decisión de diferentes actores, teniendo por entendido que lo ambiental es tarea de todos.

\section{II.3. El estudio de impacto ambiental}

\section{II.3.1. Finalidad}

El estudio de impacto ambiental (EIA), en sentido material, es el documento que contiene los resultados de una investigación multidisciplinaria y compleja sobre el entorno ambiental, socioeconómico y cultural que interactuará con un proyecto determinado. Cabe preguntarse si el EIA persigue la integración o la prevención de los impactos negativos derivados del proyecto. La respuesta a esta pregunta implica importantes diferencias en términos regulatorios.

De acuerdo con el diccionario de la Real Academia de la Lengua Española, «integrar» alude a: «1. Constituir un todo. 2. Completar un todo con las partes que faltaban. 3. Hacer que alguien o algo pase a formar parte de un todo» ${ }^{8}$. Por su parte, «prevenir», según la misma fuente, significa: «1. Preparar, aparejar y disponer con anticipación lo necesario para un fin. 2. Prever, ver, conocer de antemano o con anticipación un daño o perjuicio. 3. Precaver, evitar, estorbar o impedir algo» ${ }^{9}$. La prevención promueve una lógica anticipativa que tiene como finalidad neutralizar, mitigar o gestionar los impactos negativos sobre el entorno multidimensional ${ }^{10}$ del proyecto. En razón de ello, este enfoque

6 lbídem, p. 70.

7 Ver Our Common Future: Brundtland Report (http://worldinbalance.net/intagreements/1987brundtland.php), 1987.

8 Real academia de la Lengua Española. Diccionario de la Lengua Española. Vigésima segunda edición (http://www.rae.es/rae.html).

9 lbídem.

10 Entorno multidimensional hace alusión a las siguientes dimensiones: ambiental, social, económica y cultural. 
tiene implícita una connotación negativa, se mitiga o repara algo que es perjudicial o potencialmente peligroso.

Desde este punto de vista, los proyectos susceptibles de generar impactos perjudiciales, serían - a través del EIA — adaptados de tal forma que se minimicen las consecuencias negativas sobre su entorno. La prevención se impuso como principio del derecho ambiental desde su nacimiento y sirve de inspiración no solo al derecho positivo, sino también —como vimos anteriormente- al diseño de políticas públicas. Desde un enfoque de sistemas, el cual nos permite poner de relieve la interactividad entre derechos (derechos y ecosistemas, ecosistemas y economía, economía y sociedad, sociedad y cultura), la integración se revela como más coherente con lo que persiguen los derechos y las políticas ambientales, de ahí que el autor se incline por preferirla como la finalidad lógica del EIA. En este orden de ideas, si concebimos el entorno como un conjunto de sistemas relacionados y en interacción, el proyecto vendría a ser un nuevo componente del sistema, el cual deberá integrarse armónicamente con el resto de partes. Desde esta perspectiva, un puente, una central hidroeléctrica o una planta petroquímica serían concebidos integrados a su entorno en múltiples dimensiones, vale decir: ambiental, social, cultural y económica.

Asimismo, la integración, a diferencia de la prevención, no contiene un sentido negativo, por el contrario, podría significar unión, armonía, equilibrio o complemento. Si bien la prevención representa uno de los principios más relevantes del derecho ambiental y de las políticas ambientales, connota la imposición del proyecto sobre el entorno. La integración, aunque es vista como un concepto nuevo, en tanto concepto heredero de la teoría general de sistemas en realidad nos remonta a nuestros orígenes, cuando lo seres humanos nos veíamos como parte indisoluble de la naturaleza y sometidos a sus reglas. Hoy, luego de más de siete mil años de civilización, nos reencontramos con la necesidad de someternos a las leyes naturales y descubrimos en la integración el elemento clave de nuestras políticas y, por consiguiente, de nuestros instrumentos de gestión ambiental.

\section{II.3.2. Contenido del estudio de impacto ambiental}

De acuerdo con la regulación peruana ${ }^{11}$, el EIA debe contener información sobre los siguientes puntos:

- población humana;

- fauna y flora;

- suelo, aire, agua, clima y paisaje;

TRES ÁREAS EN LA EVOLUCIÓN DE LA REGULACIÓN DEL IMPACTO AMBIENTAL

THREE TOPICS TO THE EVOLUTIOS OF THE ENVIRONMETAL IMPACT ASSESSMENT 
- la estructura y funcionamiento de los ecosistemas presentes en el área;

- patrimonio cultural material e inmaterial;

- relaciones sociales;

- condiciones de habitabilidad (ruidos, vibraciones, olores y emisiones luminosas);

- descripción de la acción propuesta y los antecedentes de su área de influencia;

- la identificación y caracterización de los impactos ambientales durante todo el ciclo de duración del proyecto;

- la estrategia de manejo ambiental o la definición de metas ambientales incluyendo, según el caso, el plan de manejo, el plan de contingencias, el plan de compensación y el plan de abandono.

Los puntos mencionados son pautas generales, sin embargo, el EIA debe desarrollar los puntos contenidos en los términos de referencia (TdR) que aprueba la autoridad ambiental competente encargada de evaluar el EIA.

Los TdR constituyen un instrumento de la mayor importancia, debido a que definen los puntos que deberán ser abordados en la investigación que implica el EIA. De su correcta definición dependen, en gran parte, los alcances del EIA y su pertinencia. Por su parte, el EIA constituye un informe sistémico, en consecuencia, su valor radica en la descripción de las interacciones de los elementos antes mencionados, no en la descripción compartimentalizada de cada uno de ellos. El informe debe explicar de qué forma se relacionan e influencian recíprocamente el ser humano, la fauna y la flora, el suelo, el agua, el aire, el clima y el paisaje, los bienes materiales y el patrimonio cultural, entre otros factores objeto de estudio. Describir el juego de interacciones necesariamente implica un trabajo colaborativo y multidisciplinario que en sí mismo representa un problema y a la vez un desafío. Pensemos en las dificultades inherentes al trabajo conjunto de personas de disciplinas tan alejadas como la biología, la psicología, la economía o la sociología.

\section{II.3.3. Zona de influencia}

Otro elemento clave, y a la vez complejo, consiste en definir la zona de influencia del proyecto. Técnicamente podemos entender esta zona como aquella que:

[...] interacciona con el proyecto en términos de fuente de recursos y materias primas (recursos naturales, energía, mano de obra, etcétera), soporte de los elementos físicos (edificios, instalaciones, 
etcétera) y receptor de efluentes a través de vectores ambientales, aire, agua y suelo, así como otras salidas: empleo, conflictividad social, etcétera ${ }^{12}$.

Como puede apreciarse a partir de la definición arriba citada, el área influenciada del proyecto es aquella donde tienen lugar sus consecuencias directas o indirectas en varios planos, tanto físicos — vale decir, los relacionados con el intercambio de materia hacia y desde el proyecto y la ocupación efectiva del territorio-, como sociales. De entre ellos podemos señalar los relacionados con aspectos económicos, culturales y subjetivos, estos últimos vinculados con generación de expectativas, temores e intereses.

Desde un enfoque dirigido a la gestión temprana de los conflictos sociales, resulta de la mayor relevancia poner atención al plano social al momento de delimitar la zona de impacto directo e indirecto del proyecto. Determinar las fronteras de las zonas de influencia implica discriminar la zona afectada de la no afectada, de ahí su dificultad en términos sociales, plano en el que las fronteras se vuelven grises, indefinidas y, por lo tanto, altamente controversiales.

Asimismo, en términos físicos, la interconectividad de los ecosistemas dificulta establecer zonas diferenciadas. Podría suceder que los impactos se manifiesten muchos años después de cerrado el proyecto y en áreas lejanas al mismo. Piénsese en un relleno sanitario cuyos lixiviados se infiltran en el terreno alcanzando el acuífero a más de treinta metros por debajo de la superficie, recurso hídrico que finalmente abastece manantiales ubicados a decenas o cientos de kilómetros de distancia.

\section{II.3.4. Identificación de impactos y la percepción social}

Las características del entorno condicionarán y definirán un conjunto de interacciones potenciales con el proyecto, las cuales son visualizadas en matrices del tipo causa-efecto. Se trata de eventos complejos que generan muchas veces efectos en cadena que pueden transitar desde los componentes abióticos del ecosistema hasta los bióticos. Una vez identificados los posibles impactos, corresponde valorarlos, es decir, calificarlos, ponderarlos, expresarlos en una escala que nos permita compararlos y comunicarlos. Valorar los impactos ambientales representa una tarea compleja que debe ser emprendida teniendo presente la consecución de un valor fundamental para la viabilidad del proyecto, vale decir, la confianza de la población.

Este aspecto trascendental implica conocer la opinión de la población de la zona de influencia del proyecto a través de encuestas, entrevistas,

TRES ÁREAS EN LA EVOLUCIÓN DE LA REGULACIÓN DEL IMPACTO AMBIENTAL

THREE TOPICS TO THE EVOLUTIOS OF THE ENVIRONMETAL IMPACT ASSESSMENT 
grupos focales u otro medio de investigación social. Conocer la opinión de la población resulta un factor de la mayor importancia tanto para los promotores del proyecto como para quienes tienen la responsabilidad de elaborar el EIA. Identificar los temores o sensibilidades sociales relacionadas con algunos componentes ambientales, como el agua o la calidad de los suelos o del aire, debe servir como guía para valorar los impactos y establecer prioridades en cuanto a las estrategias y alternativas para la gestión de los mismos. La confianza se funda en percepciones y estas no necesariamente en razones ni evidencias científicas. En la construcción de las percepciones intervienen los sentimientos, los cuales, muchas veces, son determinados por detalles como el sentirse considerados, valorados y respetados. En tal sentido, la opinión de la población resulta ser un factor tan real o relevante para el proyecto como la capacidad portante del suelo sobre el que se asentará la infraestructura o la capacidad de carga de los ríos o lagos que recibirán los efluentes del proyecto.

A manera de cierre de este punto, diremos que el EIA es un estudio sistémico y multidisciplinario donde se conjugan diversas disciplinas y conocimientos en un enriquecedor debate de ciencias. Es por esta razón que el EIA es potencialmente muy controversial.

\section{II.4. La evaluación de impacto ambiental}

La evaluación de impacto ambiental es un procedimiento administrativo que tiene como objeto de análisis el estudio de impacto ambiental (EIA) y como finalidad certificar o no que el proyecto resulta compatible con su entorno (ambiental, social y cultural). Por su parte, conforme a los alcances del artículo 16 del Reglamento del SEIA, la certificación ambiental «implica el pronunciamiento de la Autoridad Competente sobre la viabilidad ambiental del proyecto, en su integridad ${ }^{13}$. En este orden de ideas, la certificación ambiental resulta ser una conclusión sobre la compatibilidad de un proyecto concebido a nivel de factibilidad ${ }^{14}$, la cual se fundamenta en la evaluación de la información contenida en el EIA.

Esta información proviene de la investigación según diversas disciplinas, algunas exactas y otras inexactas. Investigación que será sometida, teóricamente hablando, a un análisis multidisciplinario dirigido a comprobar su precisión, razonabilidad y adecuación metodológica. En este punto se revelan los enormes desafíos que plantea la actividad de evaluar un EIA, desafíos que tienen a su cargo los órganos ambientales del Estado. Aprobar o no estimaciones sobre futuras concentraciones 
de contaminantes en el aire, suelos y aguas, provenientes de fábricas, minas o puertos inexistentes, resulta una tarea tan complicada como desafiante. Si a ello se suman variables menos predecibles como la percepción humana, la opinión de la población o los efectos del proyecto sobre la integridad cultural de un pueblo indígena, la evaluación se complica mucho más al mismo tiempo que crece en discrecionalidad.

El enorme trabajo que implica la evaluación de impacto ambiental tiene como finalidad no solo fijar posición sobre la correcta concepción del proyecto en términos ambientales y sociales, sino que debe aspirar a un objetivo aun mayor. Dicho objetivo es alcanzar la credibilidad de la población sobre los resultados de la evaluación ambiental, vale decir, sobre la certificación ambiental del proyecto. En tal sentido, la población, una vez emitida la certificación ambiental, debería tener la confianza en que el proyecto ha sido sometido a un escrupuloso análisis, profesional e independiente. Análisis que ha dejado a salvo el derecho de la población a vivir en un ambiente equilibrado y adecuado al desarrollo de la vida.

\section{II.4.1. Scoping y términos de referencia}

El scoping constituye una actividad temprana en la evaluación del EIA, incluso anterior a la elaboración de este, y de acuerdo con Gómez Orea «dirigida a encuadrar dicho estudio en relación con las exigencias de la Administración, las instituciones y la percepción de la población afectada $»^{15}$. Considerando la finalidad, referida a ganar la confianza de la población, esta etapa resulta ser medular, debido a que somete al EIA a los requerimientos, intereses, temores y percepciones de la población, representantes e instituciones que podrían ser afectados positiva o negativamente por el nuevo proyecto.

Una vez levantada, comprendida y decodificada la información social de campo, el Estado debe proceder a informarle a los proponentes del proyecto y a los elaboradores del EIA los alcances del futuro EIA, los puntos críticos, así como las cuestiones socialmente sensibles que deberá responder y resolver el EIA. Toda esta información deberá ser expresa a través de comunicaciones formales y TdR. Así concebidos, los $\mathrm{TdR}$ derivan de una investigación de campo (scoping) y constituyen un referente obligatorio para el EIA, debido a que alinean este instrumento con las expectativas de la institucionalidad y población afectada, e imponen a los proyectistas los principales desafíos sociales que deberán ser abordados y resueltos prioritariamente. Actualmente la etapa de scoping no se encuentra considerada como deber efectivo del Estado, sin embargo, algunas empresas contratan servicios privados para recabar este tipo de información, la cual es usada posteriormente para la elaboración del EIA.

TRES ÁREAS EN LA

EVOLUCIÓN DE

LA REGULACIÓN

DEL IMPACTO

AMBIENTAL

THREE TOPICS TO

THE EVOLUTIOS

OF THE

ENVIRONMETAL

IMPACT

ASSESSMENT 


\section{RECOMENDACIONES REGULATORIAS PARA EL SISTEMA NACIONAL DE EVALUACIÓN DE IMPACTO AMBIENTAL}

Hastaestepuntose han presentadoen formasucintalos que consideramos los rasgos esenciales de los derechos y políticas ambientales, el EIA y la evaluación de impacto ambiental. Todos los cuales comparten una lógica sistémica, multidisciplinaria, compleja y técnica. Por su parte, el derecho ambiental, como rama autónoma del derecho, incorpora los enfoques y principios propios de la tarea de preservar o restablecer el equilibrio de los ecosistemas. Siguiendo a la profesora Carla Aceves Ávila,

[...] el derecho ambiental positivo surge en virtud de que se desarrolla a partir de problemas «modernos» o «novedosos» que no formaban parte de las necesidades ni problemática de las sociedades tradicionales; por ello, en este sentido, es producto de la transformación, tanto física como cultural, que han sufrido nuestras sociedades modernas ${ }^{16}$.

Preservar el equilibrio ecosistémico implica entender su funcionamiento, para lo cual el derecho ambiental debe valerse de múltiples disciplinas científicas, entre ellas la biología, la química, la ingeniería, la meteorología, la metrología, entre muchas más. Todas ellas nos ayudan a tomarle el pulso a nuestro planeta y aliviarle la carga que supone nuestra propia existencia. Carla Aceves denomina a esta característica: «el sustrato técnico metajurídico del derecho ambiental». Por su parte, Bustamante Alsina señala como características propias del derecho ambiental las siguientes: «a) su carácter interdisciplinario; b) carácter sistémico; c) carácter supranacional; [... f) énfasis preventivo; g) rigurosa regulación técnica; h) vocación redistributiva; i) primacía de los intereses colectivos» ${ }^{17}$.

Luego de esta breve introducción, pasaremos a esbozar recomendaciones generales que recojan el espíritu del derecho ambiental y sean compatibles con la naturaleza de los institutos descritos en el presente trabajo. Las recomendaciones tienen como eje producir confianza en las certificaciones ambientales que emite el Estado y se enfocan en los siguientes tres tópicos:

1. Finalidad del SEIA.

2. Evaluación del EIA (scoping y TdR).

16 ACEVES ÁvILA, Carla. Bases fundamentales de Derecho Ambiental mexicano. México D.F.: Porrúa, 2003, p. 73.

17 BuStAMANTE AlsinA, Jorge. Derecho Ambiental. Fundamentación y normativa. Buenos Aires: Abeledo Perrot, 1995, p. 48; citado en CAFferatTA, Néstor. «Principios de Derecho Ambiental», (http://www. idea.org.py/gfx/espanol/descargas/biblioteca/LOS_PRINCIPIOS_DEL_DERECHO_AMBIENTAL. pdf), p. 22. 
3. Independencia de los equipos de elaboración y evaluación del EIA.

\section{III.1. Finalidad del Sistema Nacional de Evaluación de Impacto Ambiental y la evaluación ambiental estratégica}

En este punto, la propuesta se traduce en, paulatinamente, reemplazar el paradigma preventivo del SEIA por el integrativo, de tal forma que se inicie la reforma de la regulación de acuerdo con la evolución de las políticas ambientales y del derecho ambiental descrita anteriormente. Nótese que la propia ley nos ofrece la oportunidad para erigir a la integración como la finalidad del SEIA al incorporar dentro del referido sistema a la evaluación ambiental estratégica (EAE).

Juan José Oñate, junto con otros autores, en el libro Evaluación ambiental estratégica, cita las siguientes definiciones de la EAE:

La evaluación ambiental de una política, plan o programa (Therivel y Partidário, 1996).

La extensión de la Evaluación de Impacto Ambiental a las políticas, planes y programas (Sadler y Verheem, 1996).

El proceso formalizado, sistemático y exhaustivo de evaluar los efectos ambientales de una política, plan o programa y sus alternativas, incluyendo la preparación de un informe acerca de los hallazgos de la evaluación, y que utiliza sus resultados para una toma de decisiones transparentes (Thérivel et al., 1992).

Un procedimiento para considerar los impactos ambientales de políticas, planes y programas en los niveles más altos del proceso de decisión, con objeto de alcanzar un desarrollo sostenible (Commonwealth Environment Protection Agency 1994) ${ }^{18}$.

La EAE, a diferencia de la evaluación de impacto ambiental o el EIA, se ubica teóricamente primero en el proceso de toma de decisión. Idealmente los proyectos deberían encontrarse previstos en los programas o planes que vienen a ser la expresión más aterrizada de las políticas públicas. De este modo, la EAE aplicada a las políticas, planes y programas facilitarían el nacimiento de proyectos mejor integrados con sus respectivos entornos.

En este orden de ideas, tanto la EAE como los demás instrumentos de gestión ambiental (IGA) deben ser conjugados de manera que todos cumplan un rol en la integración de las actividades humanas con los ecosistemas. Que la EAE y el EIA coadyuven con el objetivo de

TRES ÁREAS EN LA EVOLUCIÓN DE LA REGULACIÓN

DEL IMPACTO

AMBIENTAL

THREE TOPICS TO

THE EVOLUTIOS

OFTHE

ENVIRONMETAL

IMPACT

ASSESSMENT 
la integración depende de las posibilidades de generar sinergias entre ambos IGA. Actualmente, la regulación del SEIA no contempla zonas explícitas de engranaje entre ambos instrumentos, los cuales son regulados de manera separada e inconexa. Si bien el artículo 2 de la ley y del reglamento incluyen dentro del ámbito del SEIA a los proyectos (EIA), políticas, planes y programas (EAE); y, el reglamento, en su artículo 3, reconoce el Principio de Complementariedad de los IGA, el desarrollo regulatorio aún no logra establecer las formas en que ambos instrumentos pueden efectivamente complementarse.

De acuerdo con el artículo 19 del reglamento:

Toda autoridad sectorial, regional o local que tenga a su cargo la formulación de políticas, planes o programas susceptibles de originar implicaciones ambientales significativas, de acuerdo a los criterios que establece el presente Reglamento y priorice el MINAM, debe elaborar una Evaluación Ambiental Estratégica - EAE, que será remitida al MINAM para su evaluación y aprobación, de ser el caso, mediante la expedición de un Informe Ambiental de la Política, Plan o Programa, según corresponda; dicho informe orientará los procesos de toma de decisiones con la finalidad de prevenir daños al ambiente, según se indica en el Título III del presente Reglamento.

En tal sentido, el Ministerio del Ambiente evaluará las EAE que formulen los sectores o gobiernos regionales y locales respecto de sus políticas, planes y programas, lo que producirá un informe con recomendaciones destinadas a incorporar la dimensión ambiental en la política, plan o programa, según corresponda.

El siguiente paso podría ser establecer disposiciones que vinculen las recomendaciones de la EAE con la concepción de los proyectos públicos, público-privados y privados, derivados de estos mismos planes y programas. De esta manera se garantiza la coherencia entre los proyectos y las decisiones de políticas públicas adoptadas anteriormente.

Un ejemplo de esto último lo encontramos en España, donde el inciso 3 del artículo 28 de la ley 2/2002, del 19 de junio de 2002, Ley de la Evaluación Ambiental de la Comunidad de Madrid, en la parte referida al contenido del EIA establece que «en caso de proyectos o actividades englobados dentro de planes o programas que hayan sido sometidos al procedimiento de Análisis Ambiental, el estudio de impacto ambiental deberá recoger, de forma obligatoria, lo establecido en el informe de Análisis Ambiental» ${ }^{19}$. 
Recordemos que al igual que la evaluación de impacto ambiental, la EAE también establece la participación ciudadana, la cual se produce con ocasión de un plan o programa de desarrollo. Que la población y la institucionalidad local hayan tenido ocasión de involucrarse en la evaluación de las políticas públicas, aportando sus sugerencias e ideas, facilita el camino hacia una mejor compresión de la necesidad de los proyectos, que no vendrían a ser otra cosa que la concreta realización de lo planificado conjuntamente. En razón de ello, integrar la evaluación de impacto ambiental con la EAE constituye una interesante zona de evolución para iniciar la tarea de erigir a la integración como nueva finalidad del EIA y de la evaluación de impacto ambiental.

\section{III.2. El scoping y los términos de referencia}

El artículo 3 del reglamento, que contiene la lista de los principios del SEIA, menciona el principio de Responsabilidad Compartida, en virtud del cual «el Estado y los inversionistas privados, los organismos no gubernamentales, la población organizada y los ciudadanos, en alianza estratégica, unen esfuerzos para la gestión ambiental y la efectiva implementación del SEIA». En esta línea, el scoping representa una etapa de la evaluación del EIA donde la participación del Estado podría cobrar mucha mayor intensidad.

El interés del Estado por conocer las preocupaciones, creencias, percepciones, e intereses de las instituciones locales, la administración local y la población sobre una determinada iniciativa pública o privada, habla de un Estado diferente, proactivo, sensible y profesional; un Estado que busca recabar los insumos esenciales para la posterior tarea de evaluar el EIA en sintonía con el sentir de la población potencialmente afectada. Por ello, resulta altamente recomendable evaluar cambios en la regulación que precipiten un acercamiento más intenso entre los organismos públicos encargados de la evaluación del EIA, la población afectada y la institucionalidad local. Asimismo, estos insumos resultan fundamentales para que los proponentes del proyecto valoren y califiquen adecuadamente los posibles impactos ambientales negativos y conciban la producción de otros positivos, en sintonía con las expectativas de la población.

La propuesta consiste en institucionalizar esta etapa dentro de la evaluación de los EIA a cargo del Estado, a través de normas que indiquen la obligación de los organismos públicos de recopilar información social de campo como insumo fundamental para la elaboración de los TdR y la posterior evaluación del EIA. El artículo 13 del real decreto 1131/1988, de 30 de septiembre de 1988, por el que se aprueba el reglamento para la ejecución del real decreto legislativo 1302/1986, de 28 de junio, 
de evaluación de impacto ambiental, establece un scoping limitado y potestativo para el caso español.

Artículo 13.- Con objeto de facilitar la elaboración del estudio de impacto ambiental y cuando estime que pueden resultar de utilidad para la realización del mismo, la Administración pondrá a disposición del titular del proyecto los informes y cualquier otra documentación que obre en su poder.

A tal efecto, la persona física o jurídica, pública o privada, que se proponga realizar un proyecto de los comprendidos en el anexo del Real Decreto Legislativo 1302/1986, de 28 de junio, comunicará al órgano de medio ambiente competente la mentada intención, acompañando una memoria-resumen que recoja las características más significativas del proyecto a realizar, copia de la cual remitirá asimismo al órgano con competencia sustantiva.

En el plazo de diez días, a contar desde la presentación de la memoriaresumen, el órgano administrativo de medio ambiente podrá efectuar consultas a las personas, instituciones y administraciones previsiblemente afectadas por la ejecución del proyecto, con relación al impacto ambiental que, a juicio de cada una, se derive de aquél, o cualquier indicación que estimen beneficiosa para una mayor protección y defensa del medio ambiente, así como cualquier propuesta que estimen conveniente respecto a los contenidos específicos a incluir en el estudio de impacto ambiental, requiriéndoles la contestación en un plazo máximo de treinta día ${ }^{20}$.

En el Perú, donde la población percibe a su Estado como ausente o centralizado y en algunas ocasiones hasta parcializado, resultaría provechoso tender, a través de la regulación, puentes con la institucionalidad local y la ciudadanía. Difícilmente podrá ganarse la confianza de la población en la certificación ambiental si esta misma población siente lejano, complejo, ininteligible y completamente ajeno el proceso de evaluación de impacto ambiental que conducen las autoridades estatales centrales. De ahí la importancia de implementar, desde etapas muy tempranas, un trabajo cercano, personalizado y descentralizado, en contacto con la población y sus instituciones locales.

Lograr que la certificación ambiental produzca confianza en las zonas donde los proyectos se instalarán es una tarea que debería contemplar el esfuerzo por involucrar a la institucionalidad local. En especial a las instituciones llamadas a crear y difundir conocimiento, vale decir, 
a la academia local. En esta misma línea podría evaluarse también la participación de los colegios profesionales pertinentes. Una posibilidad es que estas instituciones intervengan de alguna manera con la elaboración de los TdR. Resulta fundamental tender puentes entre la institucionalidad central y la local de manera que se generen colaboración y sinergias en aras de una evaluación de impacto ambiental cada vez más eficiente, eficaz y certera, ya sea que la evaluación del EIA se realice centralizada o descentralizadamente. Por tal motivo, la segunda zona de evolución de la regulación sobre el SEIA la constituye la normativa sobre la evaluación de impacto ambiental; introduciéndole la etapa de scoping y generando canales institucionales para la participación de la institucionalidad local cercana al proyecto en la evaluación del EIA.

\section{III.3.Independencia de los equipos de elaboración y evaluación del estudio de impacto ambiental}

Concordemos en que la confianza en la certificación ambiental y la percepción de independencia respecto de los órganos responsables de la evaluación del EIA son caras de la misma moneda. Ahora bien, un tema de constante debate lo constituye precisamente la independencia de los equipos técnicos, tanto del equipo responsable de la elaboración del EIA - por encargo del proponente del proyecto- como del equipo de funcionarios públicos responsable de la evaluación del EIA. En el primer caso se cuestiona el hecho de que quienes formulan el EIA lo hacen en el marco de la prestación de un servicio privado y por encargo del proponente del proyecto, hecho que le restaría independencia al trabajo de la consultora ambiental. En el ámbito público se sospecha sobre la interferencia política que podría sufrir el equipo técnico de evaluación, máxime si se tiene en cuenta que una conclusión negativa de la evaluación del EIA tiene el efecto de vetar el proyecto, por lo menos en los términos inicialmente planteados. Esta situación se traducirá posteriormente en retrasos en la ejecución de gasto público o en dificultades para alcanzar las metas de inversión privada en el sector. Considerando la finalidad de la certificación ambiental de producir confianza en la población este tema resulta ser muy importante.

El marco regulatorio actual contempla algunas medidas que buscan preservar el trabajo técnico, profesional y ético de las consultoras ambientales, entre las cuales está el requisito de formar parte de un registro de entidades especializadas ${ }^{21}$ y el de establecer el carácter de declaración jurada de todo lo contenido en el EIA ${ }^{22}$. La libre iniciativa privada —que consideramos debe continuar como regla fundamental para los servicios de elaboración del EIA — promueve la competencia y,

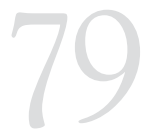

TRES ÁREAS EN LA EVOLUCIÓN DE LA REGULACIÓN DEL IMPACTO AMBIENTAL

THREE TOPICS TO THE EVOLUTIOS OFTHE

ENVIRONMETAL IMPACT

ASSESSMENT 
a través de ella, la mejora en la prestación de estos servicios. Sin embargo, la regulación podría contribuir con el mecanismo de mercado haciendo visible información resultante de la evaluación de los EIA. Información que ofrezca luces, de la forma más objetiva posible, sobre la calidad del trabajo de las referidas consultoras ambientales.

En esta línea, podría evaluarse la posibilidad de incorporar un sistema de bandas dentro de los registros públicos de empresas consultoras, el cual se organice en función de la experiencia acreditada de las consultoras y los resultados objetivos de su trabajo. Evidentemente, debería garantizarse un estándar mínimo para ingresar al registro, así como la movilidad dentro del sistema de bandas, con la finalidad de incentivar y no afectar las normas de la libre competencia. Esta propuesta es concordante con la clasificación legal de los estudios de impacto ambiental ${ }^{23}$, la cual está estructurada en función del riesgo ambiental que puede involucrar un proyecto determinado. Se trata de estimular la competencia con la finalidad de contar en la Banda 1 con las consultoras ambientales que cuenten con equipos multidisciplinarios que hayan probado la eficiencia de un trabajo en equipo, profesional e independiente.

Con relación a la independencia de los equipos técnicos encargados de la evaluación de los EIA, consideramos que resulta positivo desvincular gradualmente a las autoridades promotoras de la inversión de sus funciones de evaluación de impacto ambiental, debido al potencial conflicto de intereses. Desde esta perspectiva, la creación por la Ley 9968 del Servicio Nacional de Certificación Ambiental para las Inversiones Sostenibles (SENACE), como organismo técnico especializado, representa un paso adelante en la tarea, aún incompleta, de dotar de mayores niveles de independencia a los órganos públicos de evaluación del EIA. Sin embargo, la sujeción del jefe del SENACE, quien cuenta con la función de ser segunda instancia administrativa respecto del otorgamiento o no de las certificaciones ambientales, a un Consejo Directivo formado por seis ministros de Estado podría restarle independencia a su actuación.

Otro aspecto a tener en cuenta es que el Consejo Técnico Consultivo, conformado por especialistas convocados por el presidente del Consejo Directivo, vale decir, el ministro del Ambiente, tiene como su primera función: «absolver las dudas y consultas que formulen el presidente y el Consejo Directivo del SENACE» ${ }^{24}$. En este orden de ideas, la estructura organizacional del SENACE podría producir con cierta frecuencia opiniones divergentes entre el jefe del SENACE y el Consejo Directivo asesorado por el Consejo Técnico Consultivo. Esta posibilidad se

23 El artículo 4 de la ley contempla tres tipos de EIA en función del riesgo ambiental del proyecto: declaración de impacto ambiental, estudio de impacto ambiental semidetallado y estudio de impacto ambiental detallado.

24 Ley 29968, del 20 de diciembre de 2012, Ley de Creación del Servicio Nacional de Certificación Ambiental para las Inversiones Sostenibles (SENACE). 
ve favorecida por la naturaleza misma del EIA, que constituye una investigación multidisciplinaria, mulivariable y altamente compleja que conjuga opiniones provenientes de una amplia gama de científicos naturales y sociales que realizan elecciones dentro de un rango no necesariamente pequeño de posibilidades. En otras palabras, el EIA resulta ser en sí mismo una investigación bastante controversial.

El sistema de bandas para el registro de entidades autorizadas para realizar el EIA u otro de similares prestaciones, y el dotar de las garantías suficientes a los funcionarios públicos encargados de la evaluación del EIA son la tercera zona de evolución para la regulación del SEIA.

TRES ÁREAS EN LA

EVOLUCIÓN DE

LA REGULACIÓN

DEL IMPACTO

AMBIENTAL

THREE TOPICS TO

THE EVOLUTIOS

OF THE

ENVIRONMETAL

IMPACT

ASSESSMENT 